\title{
A model of collaborative management in disaster relief
}

\author{
Noppawan Phuengpha ${ }^{1,2^{*}}$, Bambang Supriyono ${ }^{1}$, Andy Fefta Wijaya $^{1}$, and Sujarwoto Sujarwoto ${ }^{1}$ \\ 1 Brawijaya University, Jl.MT.Haryono 163, Malang, 65145, Indonesia. \\ 2 Burapha University, 169 LongHard Bangsean Rd. Seansook, Chonburi, 20131, Thailand
}

\begin{abstract}
This paper elaborates on the collaborative management model for disaster relief by using systematic reviews. The focus point in humanitarian aids actors who collaborate in disaster relief approach. It does not focus on the collaborative management model in the subdivision of one organization. The authors' review based on a disaster event or relevant activities. The result shows that most of the collaborative management in this approach work with state level, representative of the international organization located in the affected country and international level. Less of the case that society gets involved. Some case they work with the military in term of logistics that outstanding case. This approach can explain by the umbrella's model of Proulx et al. (2014) that all actors make strategic direction and operate under an umbrella organization. The importance of obstacles is communication and networking.
\end{abstract}

\section{Introduction}

The coming of a significant amount of relief in a disaster-affected country brings a major challenge to management by humanitarian actors. The consequent can be unvalued when actors operate as single actors that follow own principle. To better management and better aid delivery, the collaborative management model is one of the mechanisms. Models do not mean increasing provision of aid, but it uses for management delivery aid to be more effective. The nature of models can enhance internal capacity for disaster relief. In international organization and subdivision in affected countries can work together. The affected country is the primary responsibility for response in a model. International actors act as a supporter of delivery through model [1].

Collaborative management model is the issue in previous papers, although most of paper present one specific focus as collaboration itself such as collaboration in logistics for humanitarian relief. Others papers present disaster management issue or model in humanitarian aid that talk in a broad perspective. It does not focus on disaster relief. Some papers present disaster event by the case that is an only humanitarian aid, but not present about collaborative management issue. Some papers descript about cooperation or coordination. Quite a few papers describe a collaborative management model in humanitarian aid or collaborative management model in disaster relief.

This paper aims to explain collaborative of humanitarian aids in case of disaster relief based on collaborative management model theory.

\section{The literature review in a collaborative management model of humanitarian aids and method}

\subsection{The literature review in the collaborative management model}

The previous researches on aftermath disaster focus on difference points: medical, health, food, donation, logistic, shelter, report after hazard events and so on. It is less collaborative management model in disaster relief term. Some collaborative framework can found from logistic aids after hazard events or from non-profit organizations. Collaborative approach researchers propose in a single approach, that is one organization. Some research are in multi-organizations to understand how they can do corporation, it is essential to understand the character of each actor.

International Organization such as the UN High commissioner for Refugees (UNHCR) and the World Food Program (WFP) operate under mandate directly from the 192 member countries. UN start aids after World War II by providing UN Relief and Rehabilitation Administration (UNRRA) to aids people across Europe. After that, it is a highly political drive by Marshall Plan. In 1951 the UN High Commissioner for Refugees (UNCHCR) was formulated. Before UNRRA finish, it encourages the UN International Children's Emergency Fund (UNICEF) to link with the Marshall Plan. The Food Agriculture Organization (FAO) create the WFP. It becomes the main provider of logistic support to humanitarian aids. In 1972 the UN established the Office

* Corresponding author: noppawan974@gmail.com 
of the Disaster Relief Coordination (UNDRO). It focuses on humanitarian aids logistic to suffer area after a disaster. It cannot get response adequately. Therefore, the UNDRO was replaced by the Office for the Coordination of Humanitarian Affairs (OCHA). It is acted as the UN Secretariat and responsible to bring together among the various humanitarian actors within the UN, and identifying a leader for humanitarian aids of all area.

The WFP is the main actor for the logistic in global hunger assistance. For managing, the UN set the UN Humanitarian Response Depot (UNHRD) network in Ghana, United Arab Emirates, Malaysia, Panama, and Italy. These hubs can enhance the WFP to quick and efficient distribution. The UNICEF also as a vital partner of the WFP. The hierarchy of the WFP gets a mandate from OCHA and the UN High Commissioner for Refugees (UNHCR). To support corporation from the military, the UN establish the Civil-Military Coordination Section. Its response to guide the international humanitarian community on civil-military coordination. The CMCS tries to response, assist and support humanitarian aids and disaster response operation. This is an initial effort of the WFP to make corporation within the UN and the military. However, for coordination with single state organization and NGOs is less.

Military is increasing in their role in humanitarian relief. In 2007 Iraq and Afghanistan, the military do logistics for humanitarian aids, and corporate with civilian government agencies, and NGOs. They focus on peacekeeping and humanitarian assistance. This case is a starting point of the collaborative between military and civilian. Logistic is noticed that plays an important role in the success or failure of the military campaign. It starts since the Alexander the Great, Hannibal Barca and the Duke of Wellington. They were interested in logistical and bring some medicine to a far area. The military had developed and improve the art of logistics and learn how to distribute adequate logistic and serve purely desire.

In 1991 the military can support logistically for food, medical care, sanitation and others emergency supplies and services. Most of the corporation between military and others actors are special agenda. The estimated amount of international NGOs is more than 40,000. The International Committee of the Red Cross (ICRC) is the oldest and the largest international HRO outside of the UN system [2]. Moreover, affected country, organization and subdivision in national level as the coordinator and the earliest response relief. It must ensure that the procedure is created a base on international aid. The status of relief items and distribution must be reported to recipient countries.

The recipient country should make cooperation with others organization before a disaster occurs. After the disaster, the affected country should try to coordinate, manage and accept teams from neighboring countries or the same region to provide help during the first 24 hours before appeal assistant from the international level. Humanitarian aids actors should do the plan for assistance, which kind is the most relevant. All actors should realize criteria might change in the context of the emergency. The operation should be flexible [3]. Noori and Weber find the factor for corporate improvement planning [4].

First, develop the response network in disaster management base on a heterogeneous worldview. Second, preparedness planning is necessary to enhance collaborative networks. Third, all humanitarian aids actors have to learn how to support local network and corporation with another level for reducing competition problem, unskilled actors and contact overload. To understand the collaborative, it will be explained in the following section.

\subsection{Collaborative management of humanitarian aids theory}

Proulx et al. propose the model of collaboration between non-profit organizations [5]. There are eight models; the full integrated merger (A), partially integrated merger (B), joint program office (C), joint partnership with affiliated programming (D), joint partnership for issue advocacy (E), joint partnership with a new formal organization $F$, joint administrative operations $(G)$ and confederation $(\mathrm{H})$. The A model is a fully integrated merger of two or more organization. They form an entirely new legal organization from the merger, a similar or complementary mission is requested. This model can occur when organizations have previously competed for funding and clients.

The B model, they still have an individual character. It occurs in a larger or stronger organization, which want to support a smaller, struggling organization. This model can solve the overlap service problem and enhance efficiency. The $\mathrm{C}$ model, they do collaborate in some program or service. The program is jointly administrated by both organizations. The lines of communication form of the joint program are the key. The D model, different organization work together on a shared project. They share a mission and serve the same population, but it does not need to serve the same services. The E model corporate to speak with one voice. It is a short-term period collaboration. They form a joint committee. The difference expertise and resources can work together without losing their independence. The $F$ model collaborates with similar missions, similar services and compete for funding. They form a new organization. The $G$ model, both organization get involved in the administrative task. They form a joint administrative office by sharing administrative personnel, financial, human resources and information technology staffs. Moreover, the $\mathrm{H}$ model is an umbrella organization. It provides services, coordination, and support to various constituent organizations. They serve across regions, including states or even countries.

Gorp and Van present data to support humanitarian aids organization [6]. He focuses on using open data and volunteer and technical communities. Trust and commitment can increase from enhancing sharing information. In the field, there is the problem with volunteer management. Some section of assistance is 
low workload because there is twenty percent volunteer base inactive. Another problem is the skill of volunteers. Because they don't have a humanitarian aids background and various difference expert type. It will take time to make a clear understanding. In addition, they face with different ways of working, flattened or decentralized structure. The top-down organization is suitable.

Affairs and Tank present four points for establishment collaborative projects [7]. The first horizontal base on peer to peer. The second reciprocity base on trust. The third sharing knowledge, and the fourth common is the collective management of the resources. The collaborative approach requires tradition approach more than financial. He also proposes the emergency management pyramid. It focuses on the local respond concept. The county level will support when the resources at the local level are not enough. If that is insufficient, the state level is requested. At the state level, there is a civilian and military approach. Base on the strategy the civilian response before the military. If both are insufficient, the governor can request the support from the central government.

In term of collaborative framework Jahre, M., \& Fabbe-Costes, N. [8] present element of a framework for collaborative development. Firstly to implement a new standard, it needs organization changing. Secondly is changing one standard, it needs changing in others relevant standard. Thirdly is changing in one organization standard, it needs other relevant organization changing. Fourthly is changing one part, it needs other parts changing. Moreover, the last is standard must include cost efficiency and flexibility in each part. Another collaborative is society and religious level as, after Indian Ocean 2004, Indonesia cooperate society found in religious level through Islam. People express the public interest at mosques. It stimulates the voice of the community and support coordination and communication. It acts as the backbone of community resilience and open assessment. The highlight of this collaborative partnership is pooling existence skill within communities and use resources of collaborative aids networks and the humanitarian community. The collaborative aids networks can provide fast, efficient and effective aids in a variety of disaster phases [9].

\section{Method}

Systematic reviews can help the expansion of the knowledge by using the relevant papers and the process encompassed planning, searching, screening and reporting [10]. The scope of this paper using the keyword collaborative management and humanitarian aid literature through Emerald Insight, Proquest, and Google Scholar $(n=805)$. Searching limit year between 2010 and 2017 that many natural disaster events occur $(n=112)$. Papers included are in the specific research area of humanitarian aid, disaster relief, disaster resilience, disaster response, cooperation/coordination in humanitarian aid and collaborative management.

Authors selected papers from the abstract review that papers that present collaborative management in international disaster relief. It does not include other disaster management cycle and single internal disaster relief $(n=65)$. Then full-text review $(n=16)$.

Addition more previous article that selected by systematic search strategy about the collaborative model. Full text of 17 papers was identified in the model of collaborative management in disaster relief that involves international actors.

\begin{tabular}{|c|c|}
\hline Database & Number of publication \\
\hline Emerald Insight & 317 \\
\hline ProQuest & 6 \\
\hline Google Scholar & 487 \\
\hline Total & 805 \\
\hline
\end{tabular}

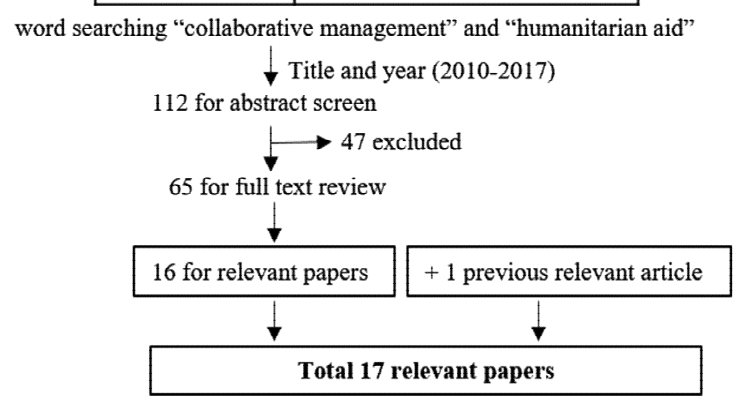

Fig. 1. The process of systematic review in this study

\section{Results and discussion}

From eight collaborative management model, there is only one model that can explain international disaster relief. The detail is explained in the next section.

\subsection{Results}

The humanitarian aids actors is international organization, such as the UN and the UN agencies, IFRC, ICRC, foreign government, government of affected country, military, society, NGOs, private sector and society [5].

One of the models was presented in the workshop on Collaborative Disaster Preparedness 2015 in Da Nang, Vietnam (Figure 2). NGOs, international organization and individual sector attended in this workshop. The aim of enhancing understanding of national and international organization actors role and improve collaborative response in disaster for the future. This model involves the military, state level, and international level. It can get a response to the large-scale disaster. Facilitation operates through military forces.

Operational in this approach can divide into two section, international level and national level, as Hesselman and Lane [11] propose. The first, international level as an international organization such as the UN. Some collaboration occurs at the regional level. Some coordination in multilateral, or bi-lateral that includes private sector and public sectors. The second is national level and all sublevel in a nation. Private sector and public sector are included. 


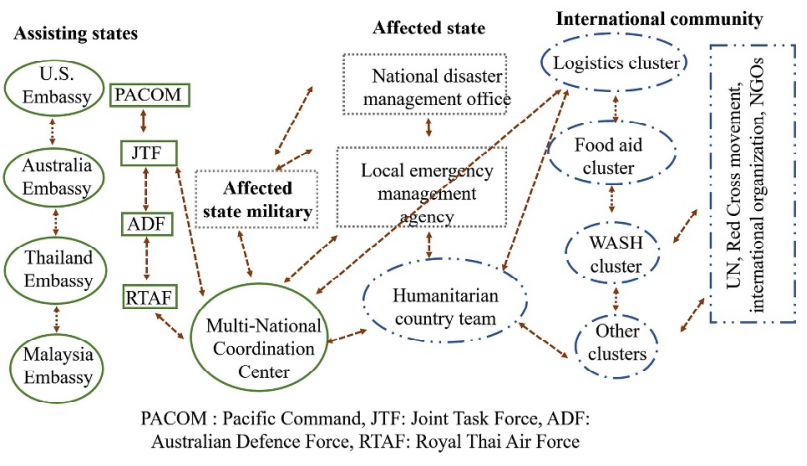

Source: States, U., \& Weilant, S. [12]

Fig. 2. Humanitarian aids actors in disaster response

Both levels involve all cycle of disaster management [11]. The integrated operation can explain the umbrella model. The aim of the workshop as the aim of the umbrella organization. The international organization as A organization. The foreign government as B organization. The affected government as C organization. NGOs as D organization. The representative of the international organization as $E$ organization. The military as F organization. These work under the umbrella organization for humanitarian aids in case of disaster relief. We can see as in the figure 3 .

\begin{tabular}{|c|c|c|c|c|c|c|}
\hline \multicolumn{7}{|c|}{$\begin{array}{l}\text { Humanitarian aids in case of disaster relief } \\
\text { (Umbrella Organization) }\end{array}$} \\
\hline$\uparrow$ & $\uparrow$ & $\uparrow$ & $\uparrow$ & $\uparrow$ & 4 & † \\
\hline $\begin{array}{c}\underline{\mathrm{A}} \\
\begin{array}{c}\text { International } \\
\text { organization }\end{array}\end{array}$ & $\underset{\substack{\text { Foreign } \\
\text { government }}}{\underline{B}}$ & $\underset{\substack{\text { Affected } \\
\text { government }}}{\mathrm{C}}$ & NGOs & $\begin{array}{c}\text { E } \\
\text { The } \\
\text { representative } \\
\text { of international } \\
\text { organization }\end{array}$ & $\underset{\text { Military }}{F}$ & $\begin{array}{l}\text { G } \\
\text { Others; } \\
\text { private } \\
\text { sector, } \\
\text { society }\end{array}$ \\
\hline
\end{tabular}

Source: adapted from E. Proulx, K., A. Hager, M., \& C. Klein, $\mathrm{K}$ [5]

Fig. 3. International humanitarian aids actors under the umbrella organization model

The umbrella model can be a potential model when multiple organization acts for different communities. This model accepts coordination across regions and countries. It provides advantages that stronger organizations share support and services. Benefits are extended, more relief area, enhance program management, better delivery services. In another hand, there is some challenge like independence within the collaboration period. Lacking trust can be a problem among actors that lead to failure of collaboration [5]. Limited resources also can affect effective collaboration and establish new relationships [6]. Sometimes it appears unwilling to work at the equal level; international actors seem to over control [1].

This figure 3 shows the horizontal coordination as Moshtari, M., \& Gonçalves, P. [12] explain. The main concept is each organization maintain the only limited corporation. It can merge not only the same level partners but also the different level of partners.

The UN delivers aid through the civil administration of the host government in each country. The UN tries to negotiate on behalf of all Humanitarian Relief organizations including NGOs when there is a conflict.
For distribution money to the recipient, the main actors are UN agencies, NGOs, and Red Cross or Red Crescent, a private organization, host governments and others. The European Union and the African Union are the biggest organization support through inter-governmental organizations. In term of government, the top three donors are the US, the European Community, and the United Kingdom.

The modus operandi of military disappear in the UN charter. The soldiers serve their own countries. The military structure requires the subordination of an individual for service in the community. In a crisis, the military can aids for the national level, especially in logistics infrastructure, they can deliver aid at a community level. The military serves under 'chain of command.' It is a line of authority and responsibility. The NGOs, it is hard to fix the modus operandi because it is a heterogeneous group. Because the high number of international NGOs make it complicated to establish the general framework. The unique of NGOs is they operate at grass root level. NGOs have a well understanding about the community. They also have a quick response to the crisis. NGOs structure is less bureaucratic when compare with the UN agencies. Therefore, it makes them are more flexible. The majority of NGOs can enter particular countries without recourse [2].

What happens in collaborative management implementation? The main problems are incorporate and friction, fear of loss of autonomy and funding rivalry. It was supproted from Colonel and Richard paper [2]. They present the obstacles in collaborative between various humanitarian relief organizations and show that the military is differences in cultural, organization or institutional, and philosophical. Factor for incorporate is a worry of autonomy loss and funding competition. Moreover, it less considered about time planning for operations and less of experience of humanitarian aids collaboration. Altay and Labonte summary integrated complexity-information flow impediment in humanitarian information management and exchange [14].

They found the impede factor consists of inaccessibility, inconsistent formats, inadequate information stream, low priority, source identification difficulty, storage media misalignment, unreliability, and unwillingness. The example case is Nepal earthquake 2015, coordination neglect appears. They fail to communicate about the real need for different humanitarian aids actors [15]. The government in the affected country has limited financial and technical capacity. Local government faces extra relief works from people out of the affected area, for example, a villager moves out from the affected village for a long time when the disaster occurs they come back and appeal for assistance. A local government attempt to manage and control the assistance distribution of INGOs. Local government register for affected people who can present identity cards [13]. this paper does not show the how well this could achieve good corporation as UNOCHA cluster system. 


\subsection{Discussion}

Collaborative experience involves a multi-level organization. In some cases found society work together with an international organization. Some cases show military gets involved in assistance. The global cluster divide into two main services; response cluster and service cluster. For emergency shelter in a disaster situation, including the UN, NGOs, the International Federation of Red Cross and Red Cross Societies (IFRC) as the lead actors. The service cluster is the supporter for Humanitarian Relief organizations. Operating among various Humanitarian Relief organizations, the information, and understanding of each other's character and modus operandi is necessary [2].

Shabudin et al. present the key to succeeding implementation in a case of south-south cooperation [16]. The first is exchange knowledge between countries of the ASEAN region and to get more opportunity for synergy the element of disaster risk management and sustainable development. The second is to establish a capacity building for designing risk reduction project with stakeholders. This project expands continually. The international organization and regional organization increase more active in disaster risk management. They try to get involved in comprehensive strategies, initiatives and mechanism development of the framework. Regional cooperation is a significant function for capacity building, supporting expert learning, knowledge management, share the experience and provide exchange activity. Increasing humanitarian response standards and overall humanitarian conditions for the long-term impact of cluster activities by OCHA In 2006, the IASC formally agree with the cluster approach that would be implemented at the global level for humanitarian coordination [17].

In term of corporate development, we can see in logistic cooperation. The WFP provides distance learning for training and professional development within the humanitarian field. The training for all Humanitarian Relief organizations and the military are to improve the effectiveness of humanitarian relief program. The training sessions help humanitarian actors learn from each other. It can improve not only a common understanding of the fundamental humanitarian aid principles but also the capacity for planning, coordinating, acting and communication between humanitarian actors. The logistic cluster website provides links to private foundations, humanitarian aids institute, and professional logistical organization.

For the humanitarian assistance procedure development, improvements are by encouraging interaction among Humanitarian Relief organizations before, during and after humanitarian assistance by support information management. Media organization must broadcast a real situation to show the real need and real effect and keep doing until the usual situation. It can influence humanitarian aids.

In the case of military collaboration, development should focus on combine agility (creativity, improvisation, and adaptability) and discipline (structure, process, and doctrine). The military role is seen as an anathema to many Humanitarian Relief organizations. Because of the military role is hard to reach the principle of humanitarian aids; humanity, neutrality, and impartiality [2].

\section{Conclusions}

The roles of humanitarian relief assistance are essential to have precise mechanisms: standard, operation plan, collaborative framework, responsibility of each actor, sufficient information and capacity building for all actors. It can trigger humanitarian actors to respond to the real needs of recipients. All humanitarian actors should be aware of operation that aid is to cover the same need. It is better to know which aid provide by whom. Add the procedure plan must be informed to other humanitarian actors.

A useful collaborative model should build capacity for all humanitarian actors by improving horizontal coordination. It is suitable for all level. An affected country should prepare all plans and strategies before the disaster. At the international level, all organizations should trust each other and leave interest behind. Good collaborative in humanitarian aids in case of disaster can provide the hygiene kits, sufficient and hygiene food, clothes, shelter, education, infrastructure. It can reach victim needs.

However, the increasing collaboration among humanitarian actors is infancy. It needs time to achieve the aims. The much progress incorporation is in the logistic term. It is between military and Humanitarian Relief organizations. This article finds out a collaborative model through disaster events cases. It less emphasizes in internal of each organization that can be focussed for the next study.

We would like to thank all previous researcher who studies in collaborative management model of humanitarian aids. These research results may lead to new relevance study.

\section{References}

1. Sandvik K.R. Adapting to Changing Needs - New Models for Humanitarian Aid in an Uncertain World (UNISDR, Swiss, 2016).

2. Colonel, L., Crichard, G. Collaborative efforts to improve logistics during humanitarian relief operations (Master Thesis, Maîtrise en études de la défense, 2011).

3. PAHO. Be a better donor: Practical Recommendations for humanitarian aid (PAHO, New York, 2009).

4. Noori, N. S., Weber, C. Dynamics of coordinationclusters in long-term rehabilitation. JHLSCM, 6,3 (2016)

5. Proulx, K., Hager, M., Klein, K. Models of collaboration between nonprofit organizations. IJPPM, 63, 6 (2014). 
6. Gorp, A., Van, F. Integration of Volunteer and Technical Communities into the Humanitarian Aid Sector: Barriers to Collaboration. Proc. ISCRAM, 1, 2 (2014).

7. Affairs, H., Tank, T. Humanitarian disruption: a collaborative approach (Sage, London 2017).

8. Jahre, M., Fabbe-Costes, N. How standards and modularity can improve humanitarian supply chain responsiveness. JHLSCM, 2, 1 (2017).

9. Bealt, J., Mansouri, S. A. From disaster to development: a systematic review of communitydriven humanitarian logistics. Disasters, 42, 1 (2018).

10. Tranfield, D., Denyer, D., Smart, P. Towards a methodology for developing evidence informed management knowledge by means of systematic review'. BJM, 14, 3 (2013).

11. Hesselman, M., Lane, L. Disasters and non-state actors - human rights-based approaches. DPM: $I J$, 26, 5 (2017).

12. States, U., Weilant, S. Collaborative Disaster Preparedness, Proceedings from Da Nang, Vietnam, 1, 2 (2015).

13. Moshtari, M., Gonçalves, P. Understanding the Drivers and Barriers of Coordination Among Humanitarian Organizations. POMS 23rd Annual Conference, Chicago, Illinois, 1, 2 (2011).

14. Shabudin, A. Syed, A., Ng, T. Learning lab on disaster risk management for sustainable development (DRM-SD). IJCCS, 3, 1 (2017).

15. Weilant, S. Preparedness (UN, New York 2015).

16. Tranfield, D., Denyer, D. Smart, P. Towards a methodology for developing evidence informed management knowledge by means of systematic review, BJM, 14,3 (2005).

17. Varella, L. Gonçalves, M. B. Collaboration: A critical success factor in the logistics of donations management (unpublished paper 2016). 